\title{
Highly efficient active colloids driven by galvanic exchange reactions
}

\author{
Linda Feuerstein, ${ }^{\dagger}$ Carl Georg Biermann, ${ }^{\ddagger}$ Zuyao Xiao, ${ }^{\dagger}$ Christian Holm, ${ }^{\ddagger}$ and \\ Juliane Simmchen*,† \\ $\dagger$ †hysical Chemistry, TU Dresden, Zellescher Weg 19, 01069 Dresden, Germany \\ $\ddagger$ Institute for Computational Physics (ICP), Allmandring 370569 Stuttgart \\ E-mail: juliane.simmchen@tu-dresden.de
}

Phone: +49351 463-37433

\section{Thermodynamic view on the formation of $\mathrm{Cu}(\mathrm{I})$}

Arguably, there is evidence that copper can be oxidized not only to $\mathrm{Cu}(\mathrm{II})$ but also to $\mathrm{Cu}(\mathrm{I})$ in the presence of chloride ions. ${ }^{1}$ Then, either the hardly soluble $\mathrm{CuCl}$ salt is formed or the chloride ions coordinate to $\mathrm{Cu}(\mathrm{I})$ to form soluble and stable complexes. In the following it is shown that, from a thermodynamical point of view, neither of these alternatives is likely to apply under the experimental conditions used here.

Given that copper is oxidized to $\mathrm{Cu}(\mathrm{I})$ the resulting overall reaction would read as:

$$
3 \mathrm{Cu}+\mathrm{AuCl}_{4}^{-} \longrightarrow 3 \mathrm{CuCl}+\mathrm{Au}+\mathrm{Cl}^{-}
$$

From this equation, the maximum concentration of dissolved $\mathrm{Cu}^{+}$and $\mathrm{Cl}^{-}$can be calucalted as $c_{0}\left(\mathrm{Cu}^{+}\right)=3 c_{0}\left(\mathrm{AuCl}_{4}^{-}\right)$and $c_{0}\left(\mathrm{Cl}^{-}\right)=4 c_{0}\left(\mathrm{AuCl}_{4}^{-}\right)$. Even for the highest concentration of $\mathrm{HAuCl}_{4}$ used in the optical microscope experiments $\left(c_{0}\left(\mathrm{AuCl}_{4}^{-}\right)=1.3 \times 10^{-5} \mathrm{moll}^{-1}\right)$ the ion product $c_{0}\left(\mathrm{Cu}^{+}\right) \times c_{0}\left(\mathrm{Cl}^{-}\right)$is less than the solubility product $K_{S}=1.72 \times 10^{-7}$ for 
$\mathrm{CuCl}$ (activity constants are neglected due to low ionic strengths). ${ }^{2}$ Therefore, it is highly unlikely that solid $\mathrm{CuCl}$ is formed.

However, $[\mathrm{CuCl}]^{0}$ could be present as a soluble complex: $\mathrm{Cu}^{+}+\mathrm{Cl}^{-} \rightleftarrows[\mathrm{CuCl}]^{0}$. For stoichiometric reasons, copper(I) chloride complexes with higher coordination numbers cannot be formed due to the lack of an other chloride source (all available $\mathrm{Cl}^{-}$ions originate from $\mathrm{HAuCl}_{4}$ which is used in very low concentrations). The stability constant for $[\mathrm{CuCl}]^{0}$ can be found in literature and reads as $K_{\text {Stab }}=\frac{c\left([\mathrm{CuCl}]^{0}\right)}{c\left(\mathrm{Cu}^{+}\right) \times c(\mathrm{Cl}-)}=10^{4.87} \cdot{ }^{3}$ In thermodynamic equibilbrium, the concentrations of the present species can then be calculated from $K_{\text {Stab }}$ using $c\left(\mathrm{Cu}^{+}\right)=c_{0}\left(\mathrm{Cu}^{+}\right)-c\left([\mathrm{CuCl}]^{0}\right)$ and $c\left(\mathrm{Cl}^{-}\right)=c_{0}\left(\mathrm{Cl}^{-}\right)-c\left([\mathrm{CuCl}]^{0}\right)$ depending on the initial concentration of $\mathrm{HAuCl}_{4}$ :

\begin{tabular}{lrrrr}
\hline$c^{0}(\mathrm{HAuCl} 4)\left[\mathrm{moll}^{-1}\right]$ & $1.6 \times 10^{-6}$ & $3.2 \times 10^{-6}$ & $6.4 \times 10^{-6}$ & $1.3 \times 10^{-5}$ \\
\hline$c\left([\mathrm{CuCl}]^{0}\right)\left[\mathrm{mol} \mathrm{l}^{-1}\right]$ & $1.3 \times 10^{-6}$ & $3.8 \times 10^{-6}$ & $1.0 \times 10^{-5}$ & $2.6 \times 10^{-5}$ \\
Fraction of $\mathrm{Cu}(\mathrm{I})$ in complex $\frac{c\left([\mathrm{CuCl}]^{0}\right)}{c_{0}\left(\mathrm{Cu}^{+}\right)}$ & 0.27 & 0.40 & 0.53 & 0.66 \\
\hline
\end{tabular}

It can be seen that only a fraction of hypothetical present $\mathrm{Cu}(\mathrm{I})$ ions can be stabilised by forming a monoligand complex due to the low concentration of $\mathrm{Cl}^{-}$. The remaining solvated $\mathrm{Cu}^{+}$are unstable in aqueous media and can undergo the highly favorable disproportionation reaction to form the solvated $\mathrm{Cu}^{2+}$ as well as elementary copper that again can undergo galvanic exchange with $\mathrm{HAuCl}_{4}$. This reaction then shifts the equilibrium of the complex forming reaction towards the side of the free ions, so that the fraction of soluted $[\mathrm{CuCl}]^{0}$ complex becomes vanishingly small. Overall, it can be seen that the amount of chloride in solution is not enough to have a stabilising effect on $\mathrm{Cu}(\mathrm{I})$ ions and the formation of $\mathrm{Cu}(\mathrm{II})$, which does not form stable chloride complexes under the given conditions, ${ }^{3}$ is the more likely reaction for the galvanic exchange.

\section{Statistical Analysis for Particle Tracking}

Brownian Motion For the $2 \mu \mathrm{m} \mathrm{Cu@SiO}$ particles, the values for Brownian Motion are determined as $(3.69 \pm 0.41) \mathrm{\mu m} \mathrm{s}^{-1}$ (for $30 \mathrm{~nm} \mathrm{Cu}$-coating) and $(4.15 \pm 0.84) \mathrm{\mu m} \mathrm{s}^{-1}$ (for $15 \mathrm{~nm}$ 
$\mathrm{Cu}$-coating). For the $3 \mu \mathrm{m}$ particles, the values are $(3.18 \pm 0.31) \mu \mathrm{m} \mathrm{s}^{-1}$ and $(3.54 \pm 0.31) \mu \mathrm{m} \mathrm{s}^{-1}$, respectively.
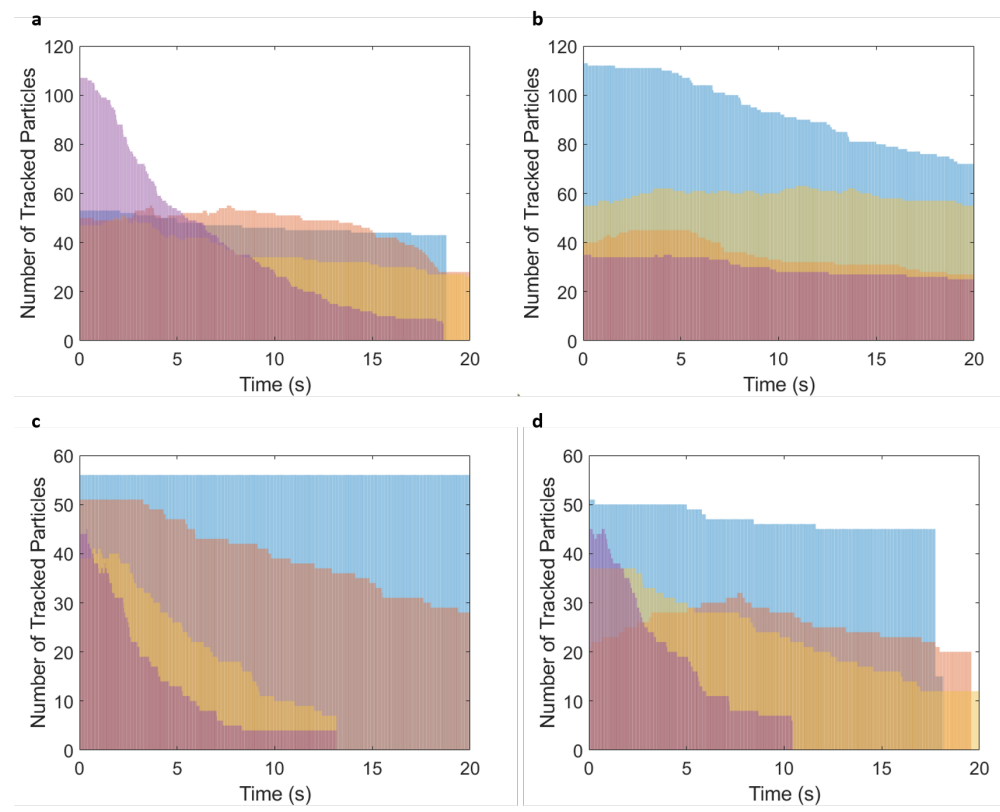

\begin{tabular}{|l|l|l|l|l|l|l|l}
$1.6 \cdot 10^{-6} \mathrm{~mol} / \mathrm{L}$ & $3.2 \cdot 10^{-6} \mathrm{~mol} / \mathrm{L}$ & $6.4 \cdot 10^{-6} \mathrm{~mol} / \mathrm{L}$ & $1.3 \cdot 10^{-5} \mathrm{~mol} / \mathrm{L}$ \\
\hline
\end{tabular}

Figure S1: Sample size (number of particles) used to calculate mean instantaneous speeds and standard deviations at each frame. Particle sizes and thickness of copper coating being a $2 \mu \mathrm{m}, 30 \mathrm{~nm}, \mathbf{b} 2 \mu \mathrm{m}, 15 \mathrm{~nm}, \mathbf{c} 3 \mu \mathrm{m}, 30 \mathrm{~nm}$ and $\mathbf{d} 3 \mu \mathrm{m}, 15 \mathrm{~nm}$, respectively. 


\section{Particle orientation}

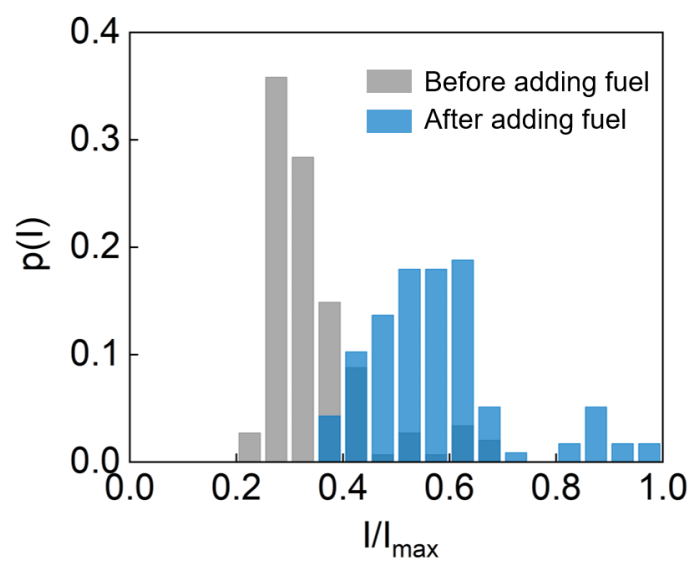

Figure S2: Probability distribution of normalized brightness for $\mathrm{Cu} @ \mathrm{SiO}_{2}$ particles before and after adding fuel. Low brightness corresponds to particles whose cap tends more towards the bottom.

\section{Average instantaneous speeds}
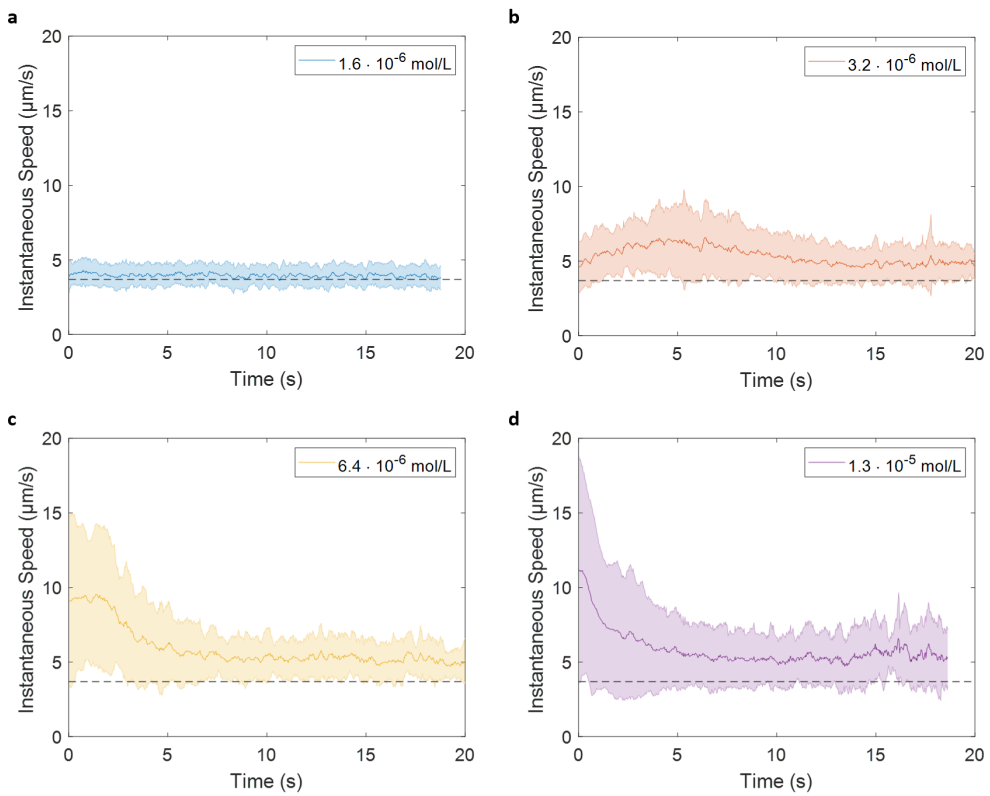

Figure S3: Average instantaneous speeds of $\mathrm{Cu} @ \mathrm{SiO}_{2}$ particles (diameter: $2 \mu \mathrm{m}$, thickness of copper coating: $30 \mathrm{~nm})$. The initial fuel concentration $c\left(\mathrm{HAuCl}_{4}\right)$ is $\mathbf{a} 1.6 \mu \mathrm{mol} \mathrm{L}-1, \mathbf{b}$ $3.2 \mu \mathrm{mol} \mathrm{L}-1, \mathbf{c} 6.4 \mu \mathrm{mol} \mathrm{L}-1$ and $\mathbf{d} 13 \mu \mathrm{mol} \mathrm{L}^{-1}$. The shaded area represents the standard deviation and dashed lines represent the speed of Brownian Motion. 

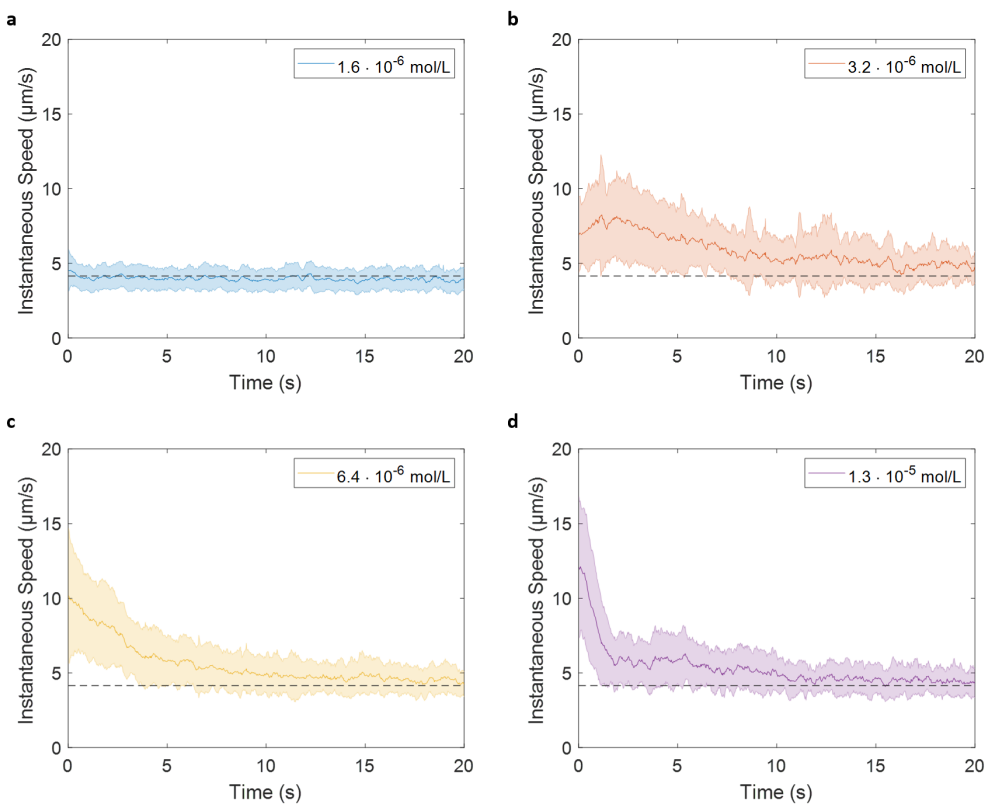

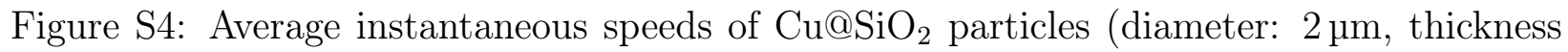
of copper coating: $15 \mathrm{~nm})$. The initial fuel concentration $c\left(\mathrm{HAuCl}_{4}\right)$ is a $1.6 \mu \mathrm{mol} \mathrm{L} \mathrm{L}^{-1}, \mathbf{b}$ $3.2 \mu \mathrm{mol} \mathrm{L}{ }^{-1}$, c $6.4 \mu \mathrm{mol} \mathrm{L}{ }^{-1}$ and $\mathbf{d} 13 \mu \mathrm{mol} \mathrm{L}^{-1}$. The shaded area represents the standard deviation and dashed lines represent the speed of Brownian Motion.
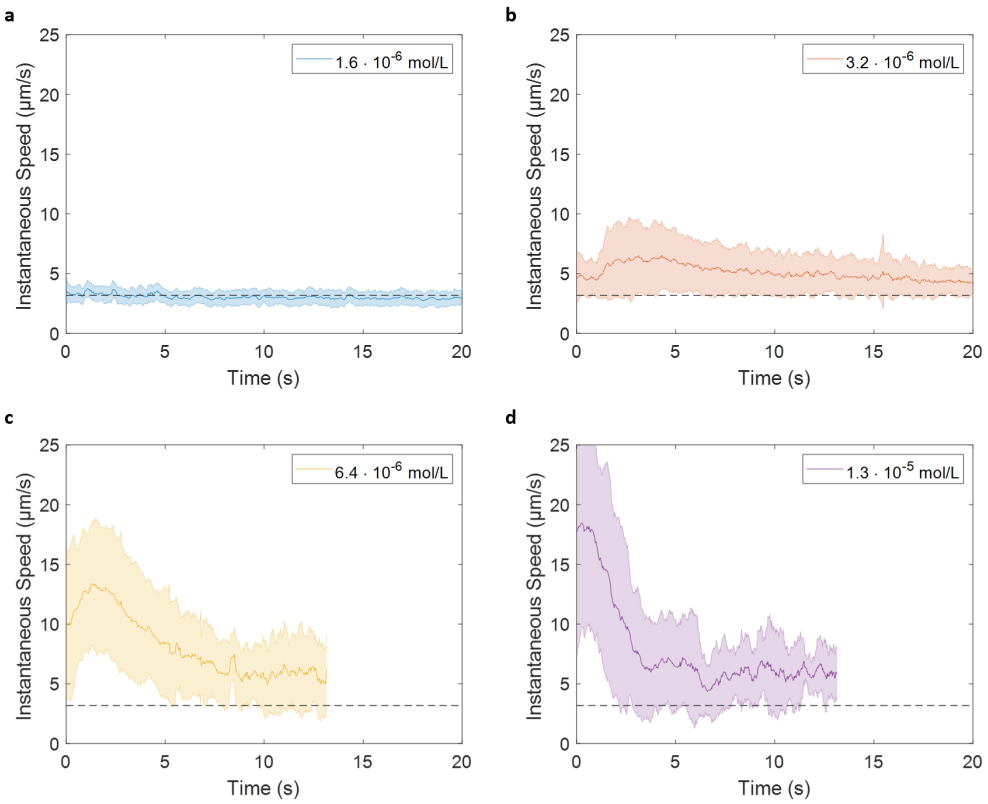

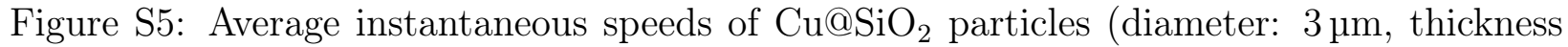
of copper coating: $30 \mathrm{~nm})$. The initial fuel concentration $c\left(\mathrm{HAuCl}_{4}\right)$ is a $1.6 \mu \mathrm{mol} \mathrm{L} \mathrm{L}^{-1}, \mathbf{b}$ $3.2 \mu \mathrm{mol} \mathrm{L}{ }^{-1}$, c $6.4 \mu \mathrm{mol} \mathrm{L}-1$ and $\mathbf{d} 13 \mu \mathrm{mol} \mathrm{L}^{-1}$. The shaded area represents the standard deviation and dashed lines represent the speed of Brownian Motion. 

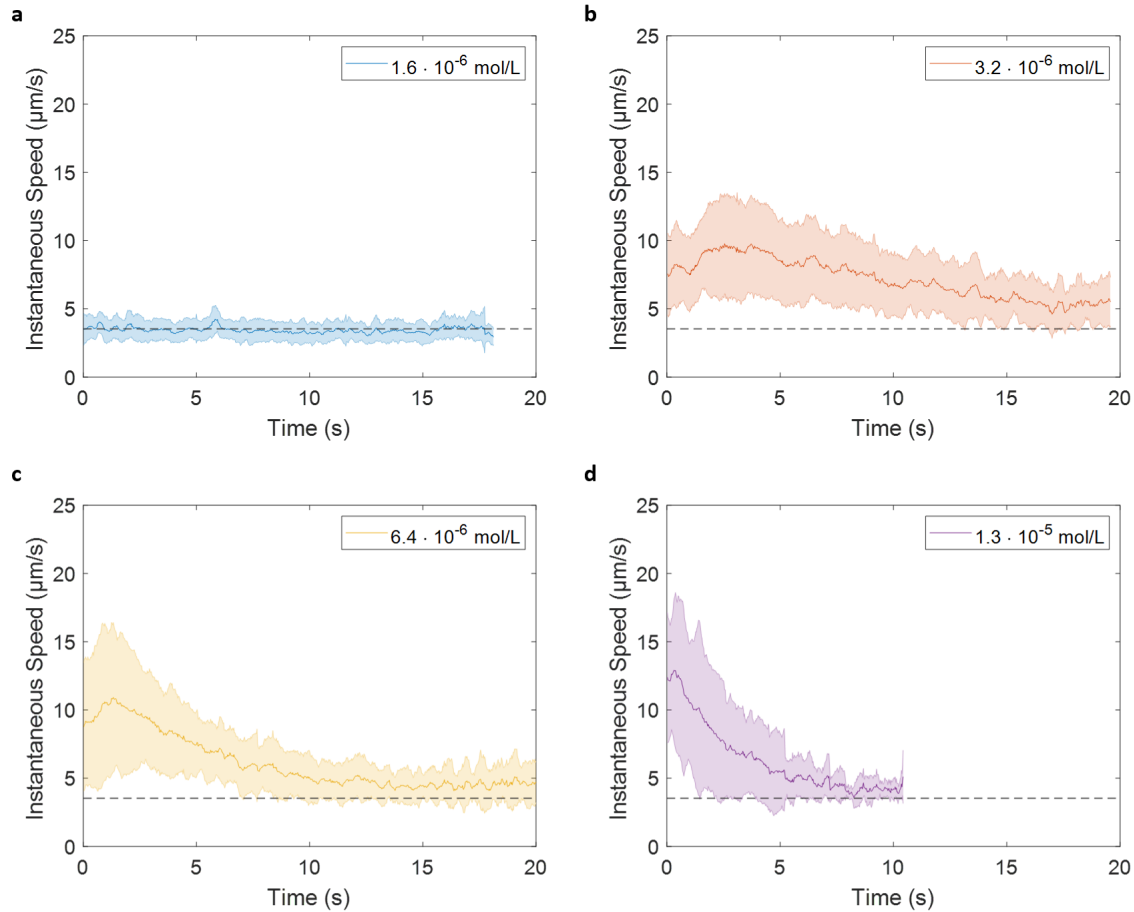

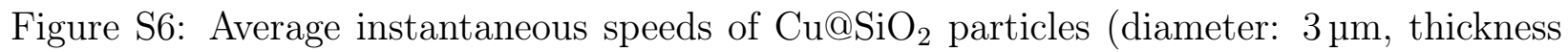
of copper coating: $15 \mathrm{~nm})$. The initial fuel concentration $c\left(\mathrm{HAuCl}_{4}\right)$ is a $1.6 \mu \mathrm{mol} \mathrm{L}{ }^{-1}, \mathbf{b}$ $3.2 \mu \mathrm{mol} \mathrm{L}{ }^{-1}$, c $6.4 \mu \mathrm{mol} \mathrm{L}-1$ and $\mathbf{d} 13 \mu \mathrm{mol} \mathrm{L}^{-1}$. The shaded area represents the standard deviation and dashed lines represent the speed of Brownian Motion.

\section{New Addition of Fuel}

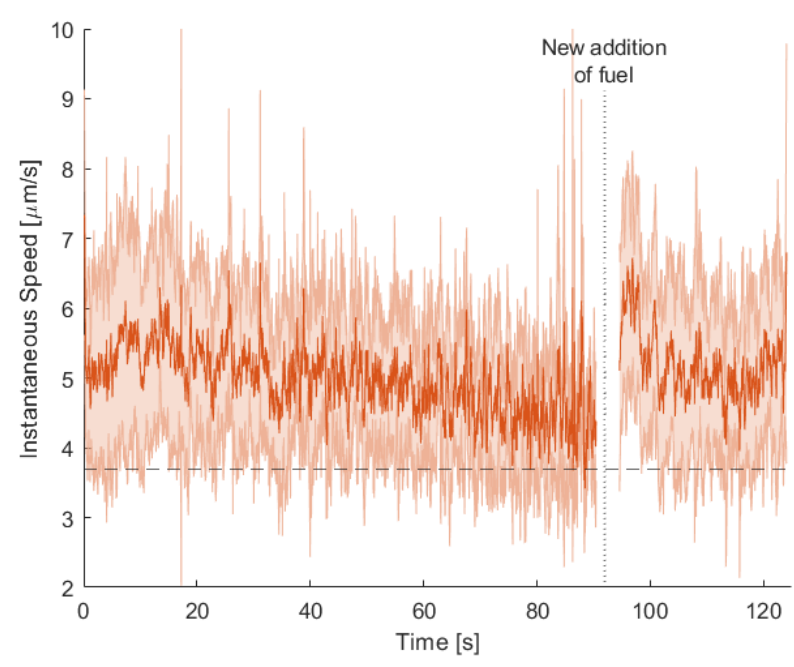

Figure S7: New addition of fuel $\left(c\left(\mathrm{HAuCl}_{4}\right)=3.2 \mu \mathrm{mol} \mathrm{L}{ }^{-1}\right)$, Particle size: $2 \mu \mathrm{m}$, thickness of copper coating: $30 \mathrm{~nm}$. The dashed line represents the speed of Brownian Motion. 


\section{Zeta Potentials}

Table S1: Zeta potential values in $\mathrm{mV}$.

\begin{tabular}{|c|c|c|}
\hline $\mathrm{SiO}_{2}$ particles & $\mathrm{Cu}$ particles & $\mathrm{Cu} @ \mathrm{SiO}_{2}$ \\
\hline$-44.1 \pm 0.6$ & $-3.14 \pm 0.48$ & $-30.5 \pm 3.8$ \\
\hline
\end{tabular}

The Zeta potentials were measured using a Malvern Zetasizer Nano ZSP.

\section{Supporting Videos}

Video $\mathrm{S} 1 \quad \mathrm{Cu} @ \mathrm{SiO}_{2} 2 \mu \mathrm{m}$ particles at concentrations ranging from 1.6 to $13 \mu \mathrm{mol} \mathrm{L}{ }^{-1} \mathrm{HAuCl}_{4}$, real speed.

Video S2 $\mathrm{Cu} @ \mathrm{SiO}_{2} 2 \mu \mathrm{m}$ particles at a concentration of $3.2 \mu \mathrm{mol} \mathrm{L}-1 \mathrm{HAuCl}_{4}$ with a second addition after about $90 \mathrm{~s}$, real speed.

Video S3 development of the cap structure visualized using $3 \mu \mathrm{m} \mathrm{Cu} @ \mathrm{SiO}_{2}$ particles at a concentrations of $0.25 \mathrm{mmol} \mathrm{L}^{-1} \mathrm{HAuCl}_{4}$, speed as indicated.

All videos are recorded with 40 frames per second and are played at 30 frames per second.

\section{Modelling}

\section{Concentrations}

The bulk concentrations correspond to the concentrations at the outer edge of the simulation domain and enter the model merely as a boundary condition. We assume that the only two substances in the bulk solution are the fuel chloroauric acid, and carbonic acid, as is usual for solutions in contact with air. We assume that no $\mathrm{Cu}^{2+}$ and $\mathrm{Cl}^{-}$has been produced yet (as it would be the case in early stages of the reaction), hence we do not account for the reaction products in the bulk concentrations (i.e. $\left.c\left(\mathrm{Cu}_{2}{ }^{+}\right)=0\right)$. However, in the simulation we do not set $c\left(\mathrm{Cl}^{-}\right)=0$, because we have to account for ambient ions, which are always 
Table S2: Parameter choice for the finite elements simulation, if not specified otherwise.

\begin{tabular}{lll}
\hline Parameter & Value & Description \\
\hline$r$ & $1.0 \mu \mathrm{m}$ & particle radius \\
$R$ & $18.5 \times r$ & radius of the simulation domain \\
$T$ & $298 \mathrm{~K}$ & temperature \\
$\epsilon_{\mathrm{r}}$ & 79 & relative permittivity of the fluid \\
$\mu$ & $8.91 \times 10^{-4} \mathrm{Pas}$ & dynamic viscosity of the fluid \\
$\sigma$ & $-3.0 \times 10^{-4} \mathrm{C} \mathrm{m}^{-2}$ & charge density at the particle's surface \\
$k_{1}$ & $1.0 \mu \mathrm{mol} \mathrm{m}^{-2} \mathrm{~s}^{-1}$ & surface reaction rate \\
$k_{2}$ & $0.2 \mathrm{~m} \mathrm{~s}^{-1}$ & rate limiting behavior (see text) \\
\hline$c\left(\mathrm{AuCl}_{4}-\right)$ & $6.4 \mu \mathrm{mol} \mathrm{L}^{-1}$ & $\mathrm{AuCl}_{4}^{-}$bulk concentration \\
$c\left(\mathrm{H}^{+}\right)$ & $c\left(\mathrm{AuCl}_{4}^{-}\right)+c\left(\mathrm{Cl}^{-}\right)$ & $\mathrm{H}^{+}$bulk concentration \\
$c\left(\mathrm{Cl}^{-}\right)$ & $3.0 \mu \mathrm{mol} \mathrm{L}^{-1}$ & $\mathrm{Cl}^{-}$bulk concentration \\
$c\left(\mathrm{Cu}^{2+}\right)$ & $0 \mu \mathrm{mol} \mathrm{L}^{-1}$ & $\mathrm{Cu}^{2+}$ bulk concentration \\
\hline$D_{\mathrm{AuCl}_{4}-}$ & $1.4 \times 10^{-9} \mathrm{~m}^{2} \mathrm{~s}^{-1}$ & Diffusivity of $\mathrm{AuCl}_{4}^{-4,5}$ \\
$D_{\mathrm{H}^{+}}$ & $9.31 \times 10^{-9} \mathrm{~m}^{2} \mathrm{~s}^{-1}$ & Diffusivity of $\mathrm{H}^{+6}$ \\
$D_{\mathrm{Cl}^{-}}$ & $2.03 \times 10^{-9} \mathrm{~m}^{2} \mathrm{~s}^{-1}$ & Diffusivity of $\mathrm{Cl}^{-6}$ \\
$D_{\mathrm{Cu}^{2+}}$ & $0.71 \times 10^{-9} \mathrm{~m}^{2} \mathrm{~s}^{-1}$ & Diffusivity of $\mathrm{Cu}^{2+6}$ \\
\hline & & \\
\hline
\end{tabular}

present. To save computational cost, we treat $\mathrm{HCO}_{3}{ }^{-}$as $\mathrm{Cl}^{-}$, saving one unknown quantity to solve for. It can be shown that this is equivalent to treating $\mathrm{HCO}_{3}{ }^{-}$as a separate species.

\section{Meshing and discretization}

The mesh is triangular for most of the simulation domain. In a semi circular region of height $0.5 \mu \mathrm{m}$ on top of the particle's surface, a quadrilateral mesh is employed. The radial dimension of the domain elements shrinks towards the surface to be able to resolve the thin electrochemical double layer. Directly at the surface their height is $1 \mathrm{~nm}$. The mesh consists of around 24000 domain elements in total. All quantities are discretized with second order polynomials on each domain element.

\section{Reaction rate}

The surface reaction rate $k_{1}$ from table $\mathrm{S} 2$ is employed at the active side of the particle. At its passive side, the reaction rate is set to 0 . There is a smooth transition between 0 and 
$k_{1}$ at the equator within $0.1 \mathrm{rad}$. The surface reaction rate is given in terms of the overall reaction

$$
2 \mathrm{AuCl}_{4}^{-}+3 \mathrm{Cu} \longrightarrow 2 \mathrm{Au}+3 \mathrm{Cu}^{2+}+8 \mathrm{Cl}^{-}
$$

which means that the consumption rate of $\mathrm{AuCl}_{4}{ }^{-}$is $2 k_{1}$, and the production rates of $\mathrm{Cu}^{2+}$ and $\mathrm{Cl}^{-}$are $3 k_{1}$ and $8 k_{1}$, respectively.

The constant reaction rate boundary condition can lead to unphysical results in the case that not enough $\mathrm{AuCl}_{4}{ }^{-}$is transported to the surface in order to maintain a reaction of the prescribed rate. To prevent this, we limited the reaction rate by the local concentration of $\mathrm{AuCl}_{4}{ }^{-}$using the expression

$$
k_{\ell}= \begin{cases}\left(\frac{1}{k_{2} c\left(\mathrm{AuCl}_{4}^{-}\right)}+\frac{1}{k_{1}}\right)^{-1} & c\left(\mathrm{AuCl}_{4}^{-}\right)>0 \\ k_{2} c\left(\mathrm{AuCl}_{4}^{-}\right) & c\left(\mathrm{AuCl}_{4}^{-}\right) \leq 0\end{cases}
$$

for the local surface reaction rate $k_{\ell}$. The case for negative concentration is only for numerical stability of the solver. The expression for positive concentration converges to $k_{1}$ for high concentrations, and vanishes for small concentrations. The size of this transition range is controlled by $k_{2}$. We chose $k_{2}=0.2 \mathrm{~m} \mathrm{~s}^{-1}$ to obtain a very tight transition region.

\section{Efficiencies}

For calculating the efficiency, we first look at the power output, more specifically, the mechanical power output obtained from the drag force multiplied by the velocity. We assume our colloids to be perfect spheres and we simplify our calculations by considering only maximum instantaneous speed values.

$$
P_{\text {mech }}=F_{\text {drag }} v=6 \pi \mu r v^{2}=f v^{2}
$$


The parameters used here are $\mu$ as the dynamic viscosity of water $\left(8.9 \times 10^{-4} \mathrm{Ns} \mathrm{m}^{-2}\right)$, $r$ the radius of the particles (here 1 or $1.5 \mu \mathrm{m}$ ) and the factor $f$ results in $f=6 \pi \mu \mathrm{r}$ or $1.69 \times 10^{-8} \mathrm{~N} \mathrm{~s} \mathrm{~m}^{-1}$.

From this we can calculate

Table S3: Exemplary $P_{\text {mech }}$ values for $2 \mu \mathrm{m} \mathrm{Cu}_{15} @ \mathrm{SiO}_{2}$

\begin{tabular}{lll}
\hline$c\left(\mathrm{HAuCl}_{4}\right)\left[\mathrm{\mu mol} \mathrm{L}^{-1}\right]$ & max. inst. speed $\left[\mathrm{m} \mathrm{s}^{-1}\right]$ & $P_{\text {mech }}\left[\mathrm{N} \mathrm{m} \mathrm{s}^{-1}\right]$ \\
\hline 1.6 & 4.54 & $3.46 \times 10^{-19}$ \\
3.2 & 8.26 & $1.14 \times 10^{-18}$ \\
6.4 & 10.17 & $1.73 \times 10^{-18}$ \\
13 & 11.99 & $2.41 \times 10^{-18}$ \\
\hline
\end{tabular}

Equivalent values have been obtained for 2 and $3 \mu \mathrm{m}$ colloids with 15 and $30 \mathrm{~nm}$ copper layers at all concentrations, results are not shown.

The chemical power input of the micromotor is estimated using the Galvanic exchange which drives the microswimmers. Similarly to earlier approaches, ${ }^{7}$ we obtain the Gibbs free energy from the number $z$ of exchanged electrons $(z=6)$ multiplied with the Faraday constant $F$ and the standard potential difference $(E=0.66 \mathrm{~V}$, see equation 1 main manuscript).

$$
\Delta G_{\text {free }}=-z F E=-6 \times 96485 \mathrm{~A} \mathrm{~s} \mathrm{~mol}^{-1} \times 0.66 \mathrm{~V}=-382 \mathrm{~kJ} \mathrm{~mol}^{-1}
$$

If the total reaction rate $k_{\mathrm{S}}$ of a swimmer's surface is known, it can be multiplied with the Gibbs free energy to obtain the chemical power input:

$$
P_{\text {chem }}=k_{\mathrm{S}}\left|\Delta G_{\text {free }}\right|=k_{\mathrm{S}}|-z F E|
$$

With the help of simulations, we determined a theoretical upper limit to $k_{\mathrm{S}}$ by exploiting the fact that the fuel $\mathrm{AuCl}_{4}{ }^{-}$can diffuse to the particle's surface only with a finite rate. This 
upper limit depends on the bulk fuel concentration as well as various other parameters. The total reaction rate $k_{\mathrm{S}}$ is the integral of all local reaction rates $k_{\ell}$ over the swimmer's surface (or, equivalently, the total flux of $\mathrm{AuCl}_{4}{ }^{-}$to the surface). In order to find the maximally possible (local) reaction rates, we made extensive use of equation (2). $k_{1}$ must be set to be higher than the maximally possible reaction rate (if increasing $k_{1}$ doesn't change the simulation outcome, it is high enough), and $k_{2}$ must be set to a high value, ideally $\infty$, in order to pull the local concentration of $\mathrm{AuCl}_{4}{ }^{-}$as close to 0 as possible at the swimmer's active surface. With the simulation parameters shown in table S2, we obtained maximally possible reaction rates shown in table $\mathrm{S} 4$.

Table S4: Maximally possible reaction rates, simulation parameters as in table S2, and $k_{1}=5 \times 10^{-4} \mathrm{~mol} \mathrm{~m}^{-2} \mathrm{~s}^{-1}, k_{2}=0.8 \mathrm{~m} \mathrm{~s}^{-1}$

\begin{tabular}{lll}
\hline$c\left(\mathrm{AuCl}_{4}{ }^{-}\right)\left[\mathrm{mmol} \mathrm{L}^{-1}\right]$ & \multicolumn{2}{c}{$k_{\mathrm{S}}\left[\mathrm{mol} \mathrm{s}^{-1}\right]$} \\
& $r=1 \mu \mathrm{m}$ & $r=1.5 \mu \mathrm{m}$ \\
\hline 1.6 & $1.20 \times 10^{-17}$ & $1.89 \times 10^{-17}$ \\
3.2 & $2.83 \times 10^{-17}$ & $4.38 \times 10^{-17}$ \\
6.4 & $6.42 \times 10^{-17}$ & $9.83 \times 10^{-17}$ \\
13 & $1.42 \times 10^{-16}$ & $2.16 \times 10^{-16}$ \\
\hline
\end{tabular}

Finally, we simply calculate the ratio

$$
\eta=\frac{P_{\text {output }}}{P_{\text {input }}}=\frac{P_{\text {mech }}}{P_{\text {chem }}}
$$

to give the following dimensionless numbers:

Table S5: Calculated minimal efficiencies from the maximally possible chemical energy consumption and the experimentally observed velocities.

\begin{tabular}{lllll}
\hline$c\left(\mathrm{HAuCl}_{4}\right)\left[\mathrm{\mu mol} \mathrm{L}^{-1}\right]$ & $\eta\left(2 \mu \mathrm{mCu} \mathrm{un}_{15}\right)$ & $\eta\left(2 \mu \mathrm{mCu}_{30}\right)$ & $\eta\left(3 \mu \mathrm{mCu}_{15}\right)$ & $\eta\left(3 \mu \mathrm{mCu}_{30}\right)$ \\
\hline 1.6 & $7.59 \times 10^{-8}$ & $6.83 \times 10^{-8}$ & $6.31 \times 10^{-8}$ & $4.90 \times 10^{-8}$ \\
3.2 & $1.06 \times 10^{-7}$ & $6.75 \times 10^{-8}$ & $1.44 \times 10^{-7}$ & $6.46 \times 10^{-8}$ \\
6.4 & $7.09 \times 10^{-8}$ & $6.24 \times 10^{-8}$ & $8.01 \times 10^{-8}$ & $1.20 \times 10^{-7}$ \\
13 & $4.45 \times 10^{-8}$ & $3.88 \times 10^{-8}$ & $5.11 \times 10^{-8}$ & $1.04 \times 10^{-7}$ \\
\hline
\end{tabular}


The simulations leading to the reaction rates in table S4 yield much higher theoretical propulsion speeds than the experimentally observed speeds, which were used to determine the mechanical output power. This indicates that the energy input required to produce propulsion at the observed velocities could be lower and consequently, the efficiencies could be higher than the values presented in table S5.

Table S6 shows the efficiencies obtained by running simulations at reaction rates $k_{1}$ chosen to yield propulsion velocities close to the experimental maximum velocities (within $5 \%$ ). These simulations used $k_{2}=0.2 \mathrm{~m} \mathrm{~s}^{-1}$. Because friction with the substrate is not considered in these simulations, the true efficiencies are likely to lie below the values in table S6.

Table S6: Calculated maximal efficiencies from simulations which reproduce the experimentally observed velocities.

\begin{tabular}{lllll}
\hline$c\left(\mathrm{HAuCl}_{4}\right)\left[\mathrm{\mu mol} \mathrm{L}^{-1}\right]$ & $\eta\left(2 \mu \mathrm{mCu} \mathrm{u}_{15}\right)$ & $\eta\left(2 \mu \mathrm{mCu}_{30}\right)$ & $\eta\left(3 \mu \mathrm{mCu}_{15}\right)$ & $\eta\left(3 \mu \mathrm{mCu} \mathrm{u}_{30}\right)$ \\
\hline 1.6 & $1.75 \times 10^{-6}$ & $1.67 \times 10^{-6}$ & $1.68 \times 10^{-6}$ & $1.44 \times 10^{-6}$ \\
3.2 & $2.40 \times 10^{-6}$ & $2.03 \times 10^{-6}$ & $2.47 \times 10^{-6}$ & $1.82 \times 10^{-6}$ \\
6.4 & $1.93 \times 10^{-6}$ & $1.87 \times 10^{-6}$ & $1.75 \times 10^{-6}$ & $1.96 \times 10^{-6}$ \\
13 & $1.19 \times 10^{-6}$ & $1.16 \times 10^{-6}$ & $9.45 \times 10^{-7}$ & $1.06 \times 10^{-6}$ \\
\hline
\end{tabular}

Having displayed reasonable values for lower (Table S5) and upper (Table S6) estimates for the efficiencies, we conclude that the realistic efficiencies must be in the range of $10^{-7}$, which is in good agreement with the corrected results of the Sen group. ${ }^{8}$

\section{References}

(1) Deslouis, C.; Tribollet, B.; Mengoli, G.; Musiani, M. M. Electrochemical behaviour of copper in neutral aerated chloride solution. I. Steady-state investigation. J. Appl. Electrochem. 1988, 18, 374-383. 
(2) Lide, D. R., Ed. CRC Handbook of Chemistry and Physics, 90th ed.; CRC Press/Taylor \& Francis: Boca Raton, FL, CD-ROM Version 2010.

(3) Meng, Y.; Bard, A. J. Measurement of Temperature-Dependent Stability Constants of $\mathrm{Cu}(\mathrm{I})$ and $\mathrm{Cu}(\mathrm{II})$ Chloride Complexes by Voltammetry at a Pt Ultramicroelectrode. Anal. Chem. 2015, 87, 3498-3504.

(4) Tang, J.; Tian, X.-C.; Zhou, F.-Q.; Liu, Y.-Q.; Lin, J.-H. Mechanism of Au Electrodeposition onto Indium Tin Oxide. Acta Physico-Chimica Sinica 2011, 27, 641.

(5) Nakazato, Y.; Taniguchi, K.; Ono, S.; Eitoku, T.; Katayama, K. Formation dynamics of gold nanoparticles in poly(vinylpyrrolidone) and other protective agent solutions. Phys. Chem. Chem. Phys. 2009, 11, 10064-10072.

(6) Vanysek, P. In CRC Handbook of Chemistry and Physics, 101st ed.; Rumble, J. R., Ed.; CRC Press/Taylor \& Francis: Boca Raton, FL, pp 5-77-5-79, Internet Version 2020.

(7) Wang, W.; Chiang, T.-Y.; Velegol, D.; Mallouk, T. E. Understanding the Efficiency of Autonomous Nano- and Microscale Motors. Journal of the American Chemical Society 2013, 135, 10557-10565.

(8) Wong, F.; Sen, A. Progress toward light-harvesting self-electrophoretic motors: highly efficient bimetallic nanomotors and micropumps in halogen media. ACS nano 2016, 10, $7172-7179$. 